\title{
Autonomic neuropathy and vibration exposure in forestry workers
}

\author{
E HEINONEN, ${ }^{1}$ M FÄRKKILÄ, ${ }^{2}$ J FORSSTRÖM,,$^{1}$ K ANTILA, ${ }^{1}$ J JALONEN, ${ }^{1}$ \\ O KORHONEN, ${ }^{3}$ I PYYKKÖ ${ }^{3}$
}

From the Cardiorespiratory Research Unit, ${ }^{1}$ University of Turku, Turku, Department of Neurology, ${ }^{2}$ University Hospital of Helsinki, and Institute of Occupational Health Research, ${ }^{3}$ Helsinki, Finland

ABSTRACT The variation in heart rate (HRV) at rest and during deep breathing (6 cycles a minute of 88 professional lumber jacks was studied using a computer technique. The traditional indexes of HRV (CV, CVS, MEAN) were calculated and the spectral components of the HRV were alsq computed. There was a significant difference $(p<0.001)$ between the HRV indexes during the deepo breathing test in those with the shortest $(\mathrm{CV}=10 \cdot 1 \pm 1 \cdot 1)$ and those with the longest $(\mathrm{CV}=6 \cdot 2$ $\pm 0 \cdot 4$ ) exposures to vibration. The values of the HRV indexes decreased with age, but multiple regression analysis showed that the total exposure time to vibration had an independent negative association with the HRV. There were significant differences in all the frequency bands (frequency related power, FRP) of the heart rate between those with the longest and those with the shortes exposures. The HRV during a deep breathing test is associated with the activity of the parasymi pathetic nervous system and is decreased in autonomic neuropathies. Our results suggest that pro longed exposure to the vibration caused by a chain saw has a negative effect on the parasympathetie activity and thus causes autonomic dysfunction.

The vibration syndrome is composed of attacks of vascular spasms in the cold, numbness of the most affected hand, decreased muscular force, and pains in the hands and arms. ${ }^{1-3}$ The vascular spasms mimic the attacks seen in Raynaud's disease and have been considered to be due to activation of the sympathetic vasoconstrictor reflex ${ }^{4}$ through a malfunction of the central autonomic nervous system. ${ }^{5}$ Symptoms of autonomic dysfunction such as disturbances in sweating, orthostatic hypotension, sleep disturbances, and impotence have been reported to be more common among workers exposed to vibration than among referents in Japan. ${ }^{6}$ In some countries the autonomic symptoms have been classified as part of the vibration syndrome. ${ }^{7-9}$

In clinical neurology the responses of cardiovascular reflexes have been used to examine the function of the autonomic nervous system..$^{10-12}$ In the present study the changes in heart rate at rest and during deep breathing were measured using computer techniques. The aim of this study was to see whether measurable, objective findings of dysfunction of the autonomic nervous system could be detected among workers exposed to occupational vibration.

Accepted 27 August 1986

\section{Material and methods}

We studied 217 forestry workers of one employer $\frac{3}{\frac{3}{9}}$ Eighty eight professional forestry workers (mean age्ठ $43.7 \pm 8.0$, range $29-58$ ) exposed to vibration werè selected for cardiovascular tests ${ }^{13}$; their average totab sawing time was $168.9 \pm 43.0 \times 10^{2}$ hours. The stud? ies were carried out during the annual compulsory health examination and men with diabetes, $\mathrm{col}^{3}$ lagenous diseases, and hypertension were excluded.

A medical history of general health and of symptoms of autonomic nervous system functions was taken and an inquiry into the occurrence of vaso $\frac{D}{2}$ spastic episodes was made. From the medical historye. it was calculated that their mean annual intake of absolute alcohol was $3.6 \pm 4.5 \mathrm{~kg}$.

The following series of cardiovascular tests was carried out: the subject lay quietly supine for fivew minutes after which a bipolar ECG was recorded and stored on an FM tape recorder (Racal, Hythe, Southo ampton, England). The subject then breathed deeplyD according to preselected audible instructions given? from a tape recorder. A rate of six respiratory cycles? a minute (inspiration $=$ expiration $=5$ seconds) was used since this frequency has been reported to arouse maximal sinus arrhythmia in normal subjects. ${ }^{14}$ 

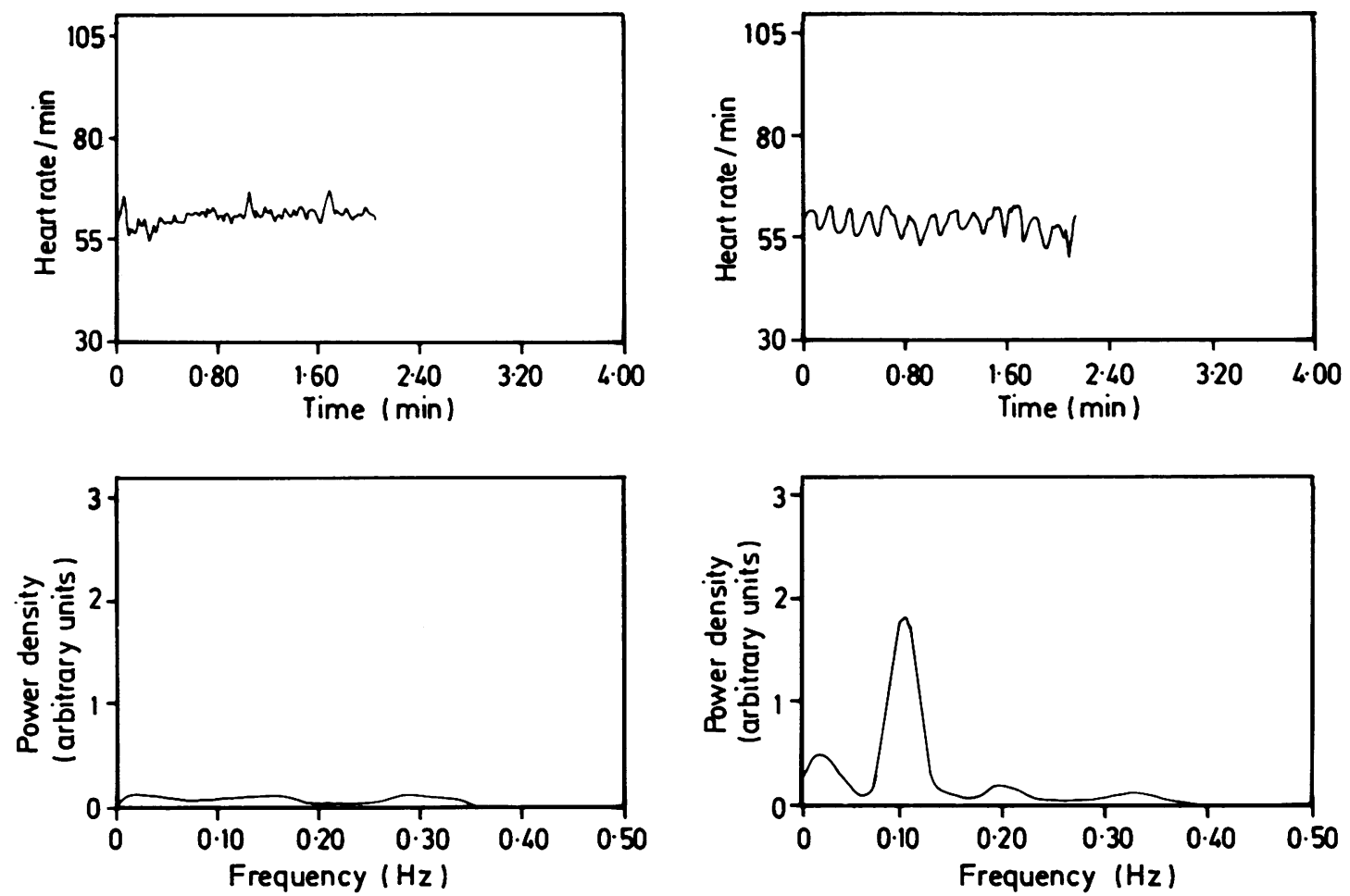

Fig 1 Heart rate of a 43 year old forestry worker at rest (upper left figure) and during deep breathing (six respiratory cycles a minute, upper right). Corresponding spectral components of heart rate are shown under these figures.

In the analysis phase the ECG was played back eight times at real time, the ECG signal was amplified, and band-pass filtered. The $R$ waves of the QRS complex were triggered by a voltage threshold trigger. The generated trigger pulses were measured and fed into a minicomputer (Eclipse c/150, Data General, Westboro, Massachusetts, USA) with the clinical data. The R-R interval vectors were trend corrected using a sixth degree polynomial trend correction. For a visual quality control of the event detection the instantaneous heart rate was in each case plotted by the computer (fig 1). Cases with ectopic cardiac arrhythmias were excluded. The following indexes were used to measure the HRV ${ }^{15}$ : the MEAN, RMSM, RMSSD, $C V$, CVS* of the R-R interval data on the resting state and deep breathing test.

\footnotetext{
*Indexes used to measure the variation in heart rate:

MEAN = Mean length of R-R intervals, $m s$.

RMSM = Root mean square of the differences from the mean $R-R$ interval, $\mathrm{ms}$; index of overall variation.

RMSSD = Root mean square of the successive $R-R$ interval differences, $\mathrm{ms}$; index of beat to beat variation.

$\mathrm{CV}=$ Coefficient of overall variation; $=100 \times$ RMSM/MEAN (\%).

CVS = Coefficient of beat to beat variation; $=100 \times$ RMSSD/MEAN (\%).
}

\section{SPECTRAL ANALYSIS}

The $R-R$ interval vectors were equispaced and low pass filtered by a digital $\sin (\mathbf{x}) / \mathbf{x}$ filter and a fast Fourier transformation programme was applied to compute the power spectra for all the ECG recordings made during both the resting state and the deep breathing test to measure the periodic components of the HRV ${ }^{1617}$ (fig 1). The whole frequency area of $0.05-0.40 \mathrm{~Hz}$ was divided into eight bands, each $0.05 \mathrm{~Hz}$ wide. The HRV power in each band, the "frequency related power" (FRP), was calculated.

\section{STATISTICAL ANALYSIS}

The whole group of forestry workers was divided into three subgroups according to total sawing time $\left(<140,140-190,>190 \times 10^{2}\right.$ hours) and into two groups according to the amount of alcohol consumed (those with a mean yearly alcohol consumption of less than $3.9 \mathrm{~kg}$ and those exceeding this level) and the occurrence of vasospastic episodes $(1=$ no episodes, $2=$ some episodes occur). The whole population was also divided according to age into three subgroups (group 1: $28-40(n=32)$; group 2: 41-50 (35); group 3: 50-58 (22)). Each of the age related subgroups was again divided according to the total vibration 
exposure time ( $=$ total sawing time), mean annual alcohol intake and the occurrence of the symptoms related to vibration induced white finger. The HRV indexes and FRP of the power spectrum of both tests were compared within each division between the respective subgroups.

Wilcoxon's test was used to test intergroup differences. The linear correlation and multiple linear regression were used to relate the HRV patterns to the clinical data.

\section{Results}

VARIATION IN HEART RATE (HRV)

The prevalence of Raynaud's phenomenon among the forestry workers was $28 \%$. If those who had not experienced an attack of Raynaud's phenomenon for two years were excluded, however, the prevalence of an active Raynaud's phenomenon was $7 \%$. The exposure to vibration increased with age and there was a highly significant difference in the total sawing time between the oldest and the youngest group of forest workers (145.3 \pm 7.6 and 191.4 \pm 9.4 $\mathrm{p}<0.0001)$. The total exposure time and age were highly significantly correlated $(\mathrm{p}<0.0001)$.

The HRV decreased with age and there was a significant difference in the HRV between the three age groups. The difference in the CV and CVS during the deep breathing test was highly significant $(p<0.0001)$ between the youngest $(28-40)$ and the oldest (50-58) groups (table 1). The heart rate did not vary significantly between the age groups.

There was a significant difference in the HRV indexes during the deep breathing test when the whole forestry worker group was divided into three subgroups according to total vibration exposure time (table 2).

To examine the effect of the vibration exposure time on the HRV indexes a multiple linear regression analysis was carried out (table 3 ). The mean R-R interval did not correlate with either age or total saw-

Table 1 Variation in heart rate (CV,CVS) and mean length of the $R-R$ interval ( $M E A N)$ of the forestry workers in the three age groups. The values of the first groups have been compared with those of the two other groups (Wilcoxon's test, ${ }^{*} p<0.05,{ }^{* *} p<0.01,{ }^{* * *} p<0.001$ )

\begin{tabular}{|c|c|c|c|}
\hline Years & $M E A N(m s)$ & $C V(\%)$ & $C V S(\%)$ \\
\hline $\begin{array}{l}\text { At rest: } \\
28-40 \\
40-50 \\
50-58\end{array}$ & $\begin{array}{l}930.1 \pm 32.5 \\
966.3 \pm 25.6 \\
938.7 \pm 31.2\end{array}$ & $\begin{array}{l}6 \cdot 5 \pm 0 \cdot 4 \\
5 \cdot 2 \pm 0 \cdot 3^{* *} \\
4 \cdot 2 \pm 0 \cdot 3^{* * *}\end{array}$ & $\begin{array}{l}4 \cdot 8 \pm 0.5 \\
3 \cdot 4 \pm 0.3 \\
2 \cdot 7 \pm 0.3^{* *}\end{array}$ \\
\hline $\begin{array}{c}\text { Deep brea } \\
28-40 \\
40-50 \\
50-58\end{array}$ & $\begin{array}{l}\text { gg test: } \\
910.0 \pm 30.0 \\
942.2 \pm 25.7 \\
930.8 \pm 31.2\end{array}$ & $\begin{array}{l}10 \cdot 0 \pm 0.9 \\
7 \cdot 4 \pm 0.4^{*} \\
6 \cdot 1 \pm 0.7^{* * *}\end{array}$ & $\begin{array}{l}7 \cdot 8 \pm 0 \cdot 8 \\
4 \cdot 9 \pm 0 \cdot 4^{*} \\
4 \cdot 0 \pm 0 \cdot 7^{* * *}\end{array}$ \\
\hline
\end{tabular}

Table $2 H R V$ values (CV,CVS) and the mean $R-R$ interval length (MEAN) of the forestry worker group divided ${ }^{\stackrel{D}{2}}$ according to the total vibration exposure time. The values of the first group with the shortest exposure time are compared with those of the two other groups with longer vibration exposure times $\left({ }^{* * *} p<0.001\right)$

\begin{tabular}{|c|c|c|c|c|}
\hline $\begin{array}{l}\text { Total } \\
\text { exposure } \\
\text { time }\left(\times 10^{2}\right. \\
\text { hours })\end{array}$ & No & $M E A N(m s)$ & $C V(\%)$ & $C V S(\%)$ \\
\hline \multicolumn{5}{|l|}{ At rest: } \\
\hline$<140$ & 25 & $942 \cdot 4 \pm 35 \cdot 1$ & $5 \cdot 8 \pm 0.4$ & $4 \cdot 3 \pm 0 \cdot 6$ \\
\hline $140-190$ & 35 & $966 \cdot 1 \pm 28 \cdot 8$ & $5 \cdot 2 \pm 0.3$ & $3 \cdot 7 \pm 0 \cdot 4^{* *}$ \\
\hline$>190$ & 28 & $926 \cdot 2 \pm 25 \cdot 3$ & $5 \cdot 2 \pm 0 \cdot 4$ & $3 \cdot 1 \pm 0 \cdot 3$ \\
\hline \multicolumn{5}{|c|}{ Deep breathing test: } \\
\hline$<140$ & 26 & $922 \cdot 5 \pm 29 \cdot 1$ & $10 \cdot 1 \pm 1 \cdot 1$ & $7 \cdot 7 \pm 1 \cdot 1$ \\
\hline $140-190$ & 35 & $954.6 \pm 28.7$ & $7.9 \pm 0.5$ & $5.3 \pm 0.5$ \\
\hline$>190$ & 28 & $908 \cdot 0 \pm 27 \cdot 3$ & $6 \cdot 2 \pm 0.4^{* * *}$ & $3 \cdot 7 \pm 0$ \\
\hline
\end{tabular}

Table 3 Relation of total vibration exposure time (sawing time) and age of the forestry workers to the mean $R-R$ interval length (MEAN) and to the HRV indexes ( $C V$, $C V S)$. The values given are the regression coefficients of the multiple linear regression analysis $\left({ }^{*} p<0.05,{ }^{* *} p<0.01\right)$

\begin{tabular}{lll}
\hline Dependent factors & Total exposure time & Age \\
\hline At rest: & & $1 \cdot 264$ \\
MEAN & -0.111 & $-0.097^{* *}$ \\
CV & -0.001 & $-0.106^{* *}$ \\
CVS & -0.003 & 0.887 \\
Deep breathing test: & 0.020 & $-0 \cdot 154^{* *}$ \\
MEAN & $-0.029^{* *}$ & $-0.120^{*}$ \\
CV & $-0.028^{* *}$ & \\
CVS & &
\end{tabular}

ing time. Both age and the total sawing time had significant negative correlation with the $\mathrm{HRV}$ indexes during the deep breathing test, but only age had $a \mathbb{D}$ significant negative correlation with the HRV indices in the resting state.

There were no significant differences in the HRV indexes between those who had vasospastic episodes? and those who had not. Nor were there any significant differences between the subgroups obtained by dividing the whole population according 8 to the amount of alcohol consumed.

SPECTRAL ANALYSIS AND FREQUENCY RELATED POWER (FRP)

The spectral analysis using the fast Fourier trans $-\mathcal{W}$ formation was carried out on the R-R interval data obtained at rest and during the deep breathing tese enabling the various spectral components of the hear rate variation to be visualised (fig 1). The whole fre-quency area ranging from $0.025 \mathrm{~Hz}$ to $0.4 \mathrm{~Hz}$ was? divided into eight bands, each $0.05 \mathrm{~Hz}$ wide. The "power" of variation within each band was calculated? and called "frequency related power" (FRP). The⿻ 


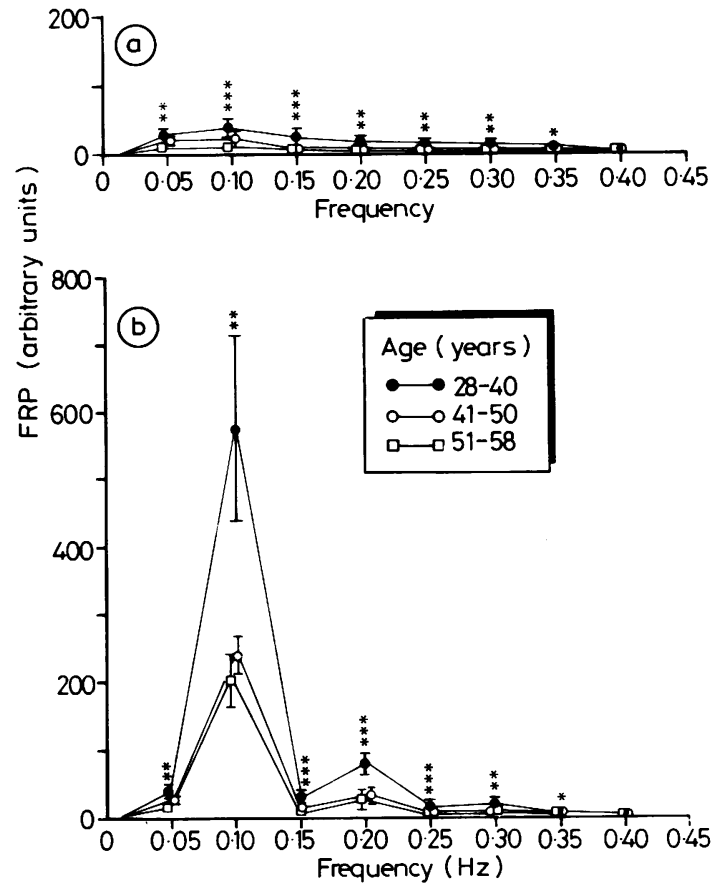

Fig 2 Frequency related power (FRP) in each frequency band (eight bands, each $0.05 \mathrm{~Hz}$ wide) in three age groups at rest ( $a$ ) and during deep breathing (b) (see text for further information). FRPs of the youngest group (28-49) have been compared with those of the two older ones (41-50 and 51-58) (Wilcoxon's test, ${ }^{*} p<0.05,{ }^{* *} p<0.01,{ }^{* * *} p<0.001$ ).

FRPs in the various frequency bands were compared between the subgroups obtained by dividing the whole group according to age, total exposure time, the occurrence of traumatic vasospastic episodes, and the amount of alcohol consumed.

The FRPs in the resting state decreased with age in all the frequency bands studied $(0.05-0.4 \mathrm{~Hz})$. There was a significant difference between the FRPs of the youngest and the oldest group between the frequencies $0.05-0.35 \mathrm{~Hz}$ (fig $2 \mathrm{a}$ ). In the deep breathing test there was a strong gathering of power around the stimulation frequency $(0 \cdot 1 \pm 0.025 \mathrm{~Hz})$. There were significant differences in the FRPs between the youngest and the two older age groups, but the differences were not so great as between the two latter ones (fig $2 b)$. When the subjects were divided into three subgroups according to the total sawing time, there were significant differences $(p<0.05)$ between the FRPs of those with a total vibration exposure time of less than $140 \times 10^{2}$ hours and those with more than $190 \times 10^{2}$ hours at rest in the frequency bands $0.05-0.25 \mathrm{~Hz}$ and in the deep breathing test in the frequency bands $0.5-0.3 \mathrm{~Hz}$ (fig 3). The division of the subjects into

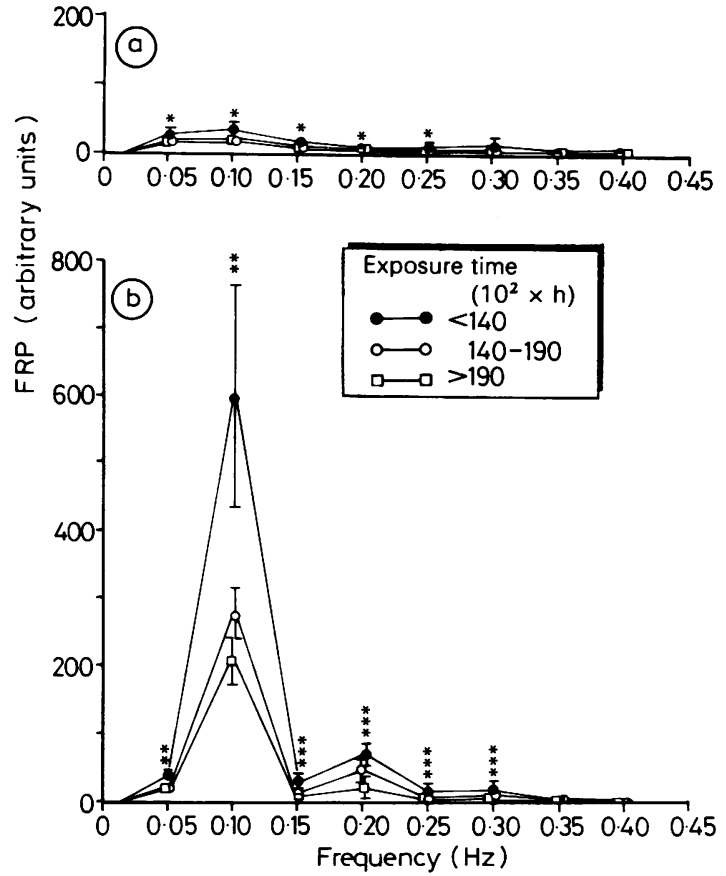

Fig 3 Frequency related power (FRP) in each frequency band in three groups divided according to total vibration exposure time. Group with shortest exposure time (less than $140 \times 10^{2}$ hours) has been compared with those with longer exposure times $\left(140-190 \times 10^{2}\right.$ hours and over $190 \times 10^{2}$ hours) (Wilcoxon's test, ${ }^{*} p<0.05, \quad{ }^{* *} p<0.01$, $* * * p<0.001)$.

two subgroups according to the occurrence of traumatic vasospastic episodes or the amount of alcohol consumed annually did not yield any significant differences between the subgroups thus created.

\section{Discussion}

The heart rate is affected by various factors in a control process aimed at maintaining cardiovascular homeostasis in the changing internal and external conditions that the body confronts. The afferent information from the arterial and cardiopulmonary mechanoreceptors and chemoreceptors is relayed from the periphery to the nucleus tractus solitarius in the brain stem. This afferent information has an effect on the output of the efferent information from the vagal nuclei and the vasomotor centre, which again are under hypothalamic control. ${ }^{18}$ The balance between the sympathetic and parasympathetic activity of the autonomic nervous system may be studied by measuring the variability in heart rate under different conditions. During respiration the heart rate rises during inspiration and begins to fall at the end of 
it and during expiration. ${ }^{14}$ It is dependent on the afferent information from the stretch receptors in the lungs and the mechanoreceptors in the right atrium. ${ }^{18}$ This respiratory arrhythmia may be abolished by giving atropine ${ }^{19}$ and is thus mostly vagally mediated. Measuring the respiratory arrhythmia gives information on the parasympathetic activity. The variability in heart rate (HRV) has been widely used to evaluate the function of the autonomic nervous system in diabetic patients and in other conditions where damage occurs to the peripheral nerve fibres. ${ }^{10-1219-21}$

In our study the HRV decreased with age, which is a physiological phenomenon. ${ }^{22}$ According to the multiple linear regression analysis the total vibration exposure time had an independent decreasing effect on the HRV indexes during the deep breathing test but not at rest. This indicates that prolonged exposure to vibration caused by a chain saw possibly has a depressing effect on the parasympathetic activity. This conclusion was reached because the respiratory arrhythmia is mostly vagally mediated. It could be postulated that a prolonged bombardment of the central nervous system with the afferent information from the Pacinian mechanoreceptors in the hand arm system causes dysfunction of the autonomic nervous system by increasing the activity of the sympathetic nervous system. The cardiovascular measurements were made at least 16 hours after occupational exposure to vibration, thus acute stress effects of vibration were excluded.

The relevance of vibration induced central dysfunction in the autonomic nervous system has been debated by Bruyn. ${ }^{23}$ Matoba et al report that digital plethysmographic responses to auditory stimuli were delayed in patients with the vibration syndrome, suggesting a disorder of the autonomic nervous system. ${ }^{24}$ Our findings, a negative association between variability in heart rate and a prolonged exposure to vibration caused by a chain saw, indicate that occupational vibration may cause autonomic dysfunction. Further studies are needed to confirm this relation, because purely correlational studies do not separate accurately enough the effects of age and the total exposure time from each other.

We are most grateful for Mrs Maija Laaksonen and Mrs Eeva Tolin for carrying out the tests and Mrs Leena Kämäräinen for typing the manuscript. The study was financially supported by Lydia Marja Julin Fund.

\section{References}

1 Agate NJ. An outbreak of cases of Raynaud's phenomenon of occupational origin. Br J Ind Med 1949;4:144-63.

2 Taylor W. Introduction. In: Taylor W, ed. Vibration syndrome. London: Academic Press, 1974:1-24.

3 Färkkilä MA. Grip force in vibration disease. Scand J Work Envi- ron Health 1978;4:159-66.

4 Hyvärinen J, Pyykkö I, Sundberg S. Vibration frequencies and amplitudes in the aetiology of the traumatic vasospastic dis? ease. Lancet 1973;i:791-4.

5 Matoba T, Kusumoto $H$. The role of higher center of the auto $\stackrel{\vec{D}}{\rightarrow}$ nomic nervous system on Raynaud's phenomenon in patientso with vibration disease. Tohoku J Exp Med 1975;115:385-92. ㄷ

6 Futatsuka M, Takamatsu M, Sakurai T, et al. Vibration hazards in forestry workers of the chain saw operators of a determined area in Japan. Journal of Science of Labour 1980;56:27-38.

7 Matoba T, Chiba M, Toshima H. Cardiovascular features of then vibration syndrome: an adaptive response. In: Brammer AJ, Taylor W, eds. Vibration effects on the hand arm in industry $\overrightarrow{0}$ New York: Wiley, 1982:25-30.

8 Drogitchina EA. The clinical picture of vibration disease. In: $\vec{\omega}$ Letaveta AA, Drogitchina EA, eds. Vibration in industry Moscow: J Zdotel'stuo "Meditsina" 1971:122-59. (Inō Russian.)

9 Gemne G. Autonomic integration of external and internal stimuli? and the Soviet concept of "diencephalic syndrome." In: Handarm vibration and the central autonomic nervous system. Jour nal of Low Frequency Noise and Vibration. 1983;1:63-8. (Spe-cial issue.)

10 Ewing DJ, Clarke BJ. Diagnosis and management of autonomic neuropathy. Br Med J 1982;285:916-8.

11 Campbell IW, Ewing DJ, Clarke BF. The quantification ofdiabetic autonomic neuropathy and its clinical significance. In $\subset$ New approaches to insulin therapy. Vienna: MTP Press, 1980.

12 Mackay JD, Page MMcB, Cambridge J, Watkins PJ. Diabetic autonomic neuropathy: the diagnostic value of heart rate mon- $\overrightarrow{0}$ itoring. Diabetologia 1980;18:471-8.

13 Färkkilä M, Aatola S, Starek J, Pyykkö I, Korhonen $O_{\text {: V V }}^{\infty}$ Vibration induced neuropathy among lumberjacks. Acta Neurol Scand 1985;71:221-5.

14 Angelo A, Coulter NA. Respiratory sinus arrhythmia: a frequency dependent phenomenon. J Appl Physiol 1984⿳亠口冋 19:479-82.

15 Tarlo PA, Välimäki I, Rautaharju PM. Quantitative computero analysis of cardiac and respiratory activity in newborn infants. J Appl Physiol 1971;31:70-5.

16 Antila K. Quantitative characterization of heart rate during exer cise. Scand J Clin Lab Invest 1979;suppl 153. (Academic dissertation.)

17 Axelrod S, Cordon D, Ubel FA, Shannon DC, Barger AC Cohen RJ. Power spectrum analysis of heart rate fluctuation: $a$ quantitative probe of beat-to-beat cardiovascular control: $\frac{\mathbb{S}}{3}$ Science 1981;213:220-2.

18. Shepherd JT, Vanhoutte PM. The human cardiovascular system New York: Raven Press, 1980.

19 Watkins PJ, Mackay JD. Cardiac denervation in diabetic neu으 ropathy. Ann Intern Med 1980;92:304-7.

20 Endre ZH, Perl SI, Kraegen EW, Charlesworth JA, Macdonald GJ. Reduced cardiac beat-to-beat variation in chronic renab failure: a ubiquitous marker of autonomic neuropathy. Clin ScD 1982;62:561-2.

21 Heinonen E, Molnar G, Lang H, Välimäki I. Computer assisted. monitoring of heart rate variation as a method of following the autonomic symptoms of the Guillain-Barre syndrome. Actă Neurol Scand 1982;65,suppl 90:232-3.

22 Smith S. Reduced sinus arrhythmia in diabetic autonomic neuropathy: diagnostic value of an age-related normal range $\sigma$ Br Med J 1982;285:1599-1601.

23 Bruyn GW. Vibration-induced central dysautonomia. Fact o응 fiction. In: Hand arm vibration and the central autonomic ner vous system. Journal of Low Frequency Noise and Vibration, $\stackrel{\infty}{\hookrightarrow}$ 1983;1:100-7. (Special issue.)

24 Matoba T, Kusumoto H, Omura H, Kotorii T, Kuwahara $H_{-}$ Takamatsu M. Digital plethysmographic responses to auditory stimuli in patients with vibration disease. Tohoku J Exp Med 1975;115:385-92. 